\title{
1 An Evaluation Tool Kit of Air Quality Micro-Sensing Units
}

2 Barak Fishbain ${ }^{1,{ }^{*,},}$, Uri Lerner ${ }^{1,+}$, Nuria Castell-Balaguer $^{2}$, Tom Cole-Hunter $^{3,4}$, Olalekan Popoola ${ }^{5}$, David M.

3 Broday $^{1}$, Tania Martinez Iñiguez ${ }^{3,4}$, Mark Nieuwenhuijsen ${ }^{3}$, Milena Jovasevic-Stojanovic ${ }^{6}$, Dusan

4 Topalovic $^{7,6}$, Roderic L. Jones ${ }^{5}$, Karen Galea ${ }^{8}$, Yael Etzion ${ }^{1}$, Fadi Kizel ${ }^{1}$, Yaela N. Golumbic ${ }^{9,1}$, Ayelet

5 Baram-Tsabari ${ }^{9}$, Tamar Yacobi $^{1}$, Dana Drahler ${ }^{1}$, Johanna A. Robinson ${ }^{10}$, David Kocman ${ }^{10}$, Milena Horvat ${ }^{10}$,

6 Vlasta Svecova ${ }^{11}$, Alexander Arpaci ${ }^{12}$, Alena Bartonova ${ }^{2}$

7

$8+$ Equally contributed

9

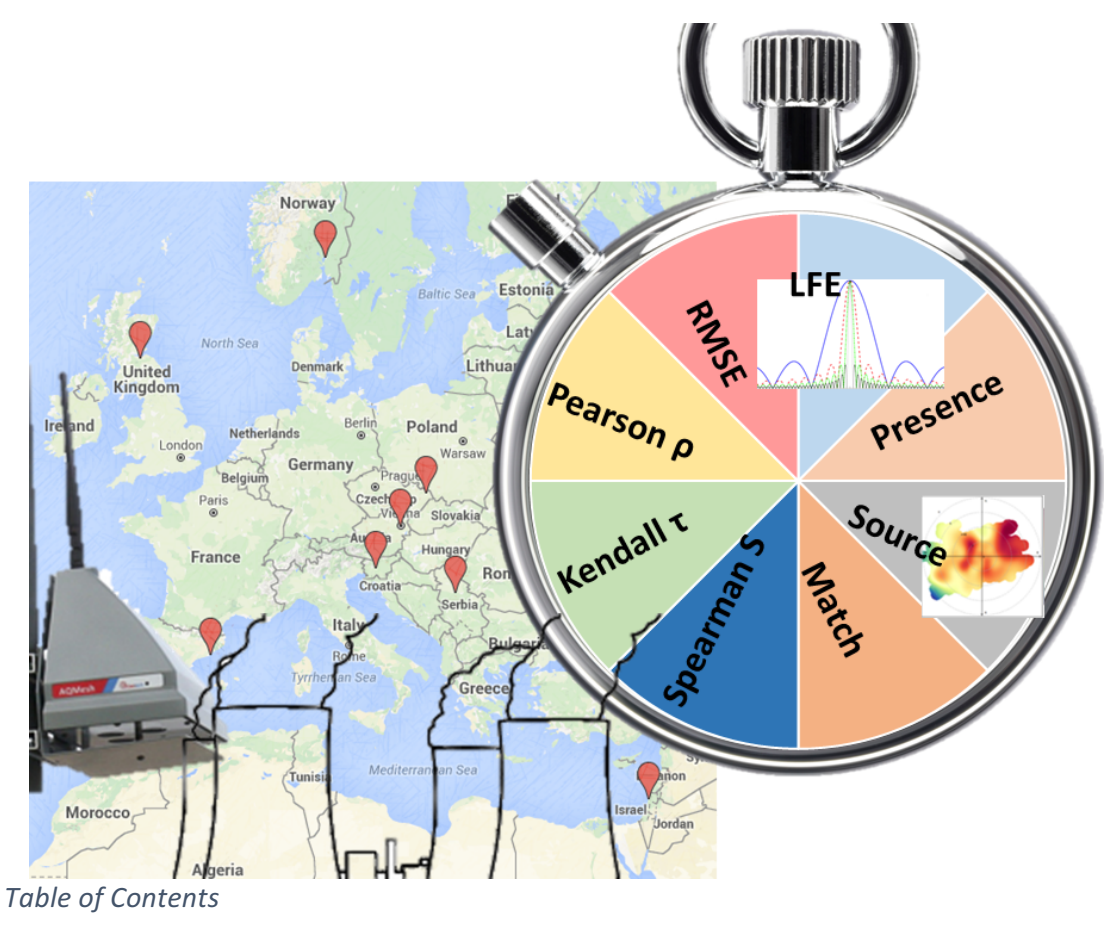

\footnotetext{
${ }^{1}$ The Technion Center of Excellence in Exposure Science and Environmental Health (TCEEH), Faculty of Civil and Environmental Engineering, Technion - Israel Institute of Technology, Haifa, Israel

${ }^{2}$ Norwegian Institute for Air Research (NILU), Kjeller, Norway

${ }^{3}$ ISGlobal, Barcelona Institute for Global Health, Barcelona, Spain

${ }^{4}$ Centro de Investigación Biomédica en Red de Epidemiología y Salud Pública (CIBERESP), Madrid, Spain

${ }^{5}$ Centre for Atmospheric Science, Department of Chemistry, University of Cambridge, Cambridge, England

${ }^{6}$ VINČA Institute of Nuclear Sciences, University of Belgrade, Belgrade, Serbia

${ }^{7}$ School of Electrical Engineering, University of Belgrade, Belgrade, Serbia

${ }^{8}$ Centre for Human Exposure Science, Institute of Occupational Medicine (IOM), Edinburgh, Scotland

${ }^{9}$ Faculty of Education in Science and Technology, Technion - Israel Institute of Technology, Haifa, Israel

${ }^{10}$ Department of Environmental Sciences, Jožef Stefan Institute, Ljubljana, Slovenia

${ }^{11}$ Department of Genetic Ecotoxicology, Institute of Experimental Medicine AS CR, Prague, Czech Republic

12 UBIMET GmbH, Vienna, Austria
} 


\section{Abstract}

Recent developments in sensory and communication technologies have made the development of portable air-quality (AQ) Micro-Sensing Units (MSUs) feasible. These MSUs allow AQ measurements in many new applications, such as ambulatory exposure analyses and citizen science. Typically, the performance of these devices is assessed using the mean error or correlation coefficients with respect to a laboratory equipment. However, these criteria do not represent how such sensors perform outside of laboratory conditions in large-scale field applications, and do not cover all aspects of possible differences in performance between the sensor-based and standardized equipment, or changes in performance over time. This paper presents a comprehensive Sensor Evaluation Toolbox (SET) for evaluating AQ MSUs by a range of criteria, to better assess their performance in varied applications and environments. Within the SET are included four new schemes for evaluating sensors' capability to: locate pollution sources; represent the pollution level on a coarse scale; capture the high temporal variability of the observed pollutant and their reliability. Each of the evaluation criteria allows for assessing sensors' performance in a different way, together constituting a holistic evaluation of the suitability and usability of the sensors in a wide range of applications. Application of the SET on measurements acquired by 25 MSUs deployed in eight cities across Europe showed that the suggested schemes facilitates a comprehensive cross platform analysis that can be used to determine and compare the sensors' performance. The SET was implemented in $\mathrm{R}$ and the code is available on the first author's website.

\section{Introduction}

Air pollution is recognized as a contributing factor to various health outcomes, and has been associated with public health risks $[1,2]$. Accurately assessing ambient concentrations of different air pollutants is necessary in any study on the impact of air quality $(A Q)$ on different health endpoints. To date, ambient pollutant concentrations are obtained from either short time-period measurement campaigns using a large number of sensing devices (e.g. [3]), or from measurements reported by standard Air Quality Monitoring (AQM) stations over extended time periods (e.g. [4]). While the former is limited in temporal representativeness (e.g. due to inter-seasonal variation), the latter is limited in spatial representativeness (e.g. due to dispersion patterns) and typically measures only a limited number of criteria pollutants [5]. Further, regulatory AQM stations require certified instrumentation meeting measurement accuracy requirements, and an extensive set of procedures to ensure that data quality remains satisfactory. These requirements, typically required by laws and regulations, ensure that measurements are comparable across all networks with similar requirements, but limit the AQM spatial deployment due to their high 
investment and operational cost. As a result, the AQM network has limited ability to account for spatial variability of pollution levels in heterogeneous regions such as urban areas, which in return, renders exposure assessment a very difficult task [6]. Moreover, the air-inlets of AQM stations are typically located on rooftops or way above the ground [7], thus misrepresenting the true exposure of any individual at head height.

Recent developments in sensory and communication technologies have made the deployment of portable and relatively low-cost Micro Sensing Units (MSUs) possible. These MSUs can operate as a set of individual nodes, or may be interconnected to form a Wireless Distributed Environmental Sensor Network (WDESN) to measure air pollution over large spatial scales. WDESNs gather high-resolution spatial and temporal data from numerous individual nodes allowing for a better interpolation and the generation of dense pollution maps, which are closer to real-life pollution dispersion scenarios [8]. The gaseous sensors mounted on these MSUs are low-power and low-cost, and are based on widely understood amperometric sensor methodologies designed for sensing selected gases at the parts-per-million (ppm) level $[9,10,11]$. Electronic circuitry, which applies signal processing, allows for the detection at the part-per-billion level [11]. Recent miniaturization of Optical Particles Counters (OPCs) [12, 13] and solid state [14, 15] sensors allows to extend the MSUs capabilities to measure Particulate Matter (PM) as well.

The small size and low power-consumption of MSUs lay the path for many new applications that require AQ data, such as exposure analyses [16, 17], education [18], hot-spot identification and characterization [19], supplementary network monitoring [20,21], and citizen science $[22,23,24]$. In particular, the essence of citizen science requires active participation of citizens in the scientific research process [22]. Within the context of air-quality research, MSUs may be deployed at citizen's homes, monitoring either ambient or indoor air quality in their local environment. An example is the CITI-SENSE project, which aims at developing sensor- based citizen observatories for improving the quality of life in cities [25].

Seminal studies that evaluate MSUs in pre-field and field trials show that these units indeed can capture air pollution spatio-temporal variation $[26,27,11,28,21,29,30]$. However, these studies have shown that the MSUs' main limitation is their low accuracy relative to laboratory equipment $[26,27,11,28,30]$ or an AQM station $[11,28,21]$.

Previously-used MSU calibration and evaluation measures, i.e., sensitivity [26, 27, 11, 28], correlation coefficient, $\rho$, coefficient of determination, $R^{2},[21,11,29]$, and the Root Mean Squared Error, RMSE [21, 29] aim at assessing the MSUs' accuracy and capability to capture trends and values of the pollutants' true ambient levels. While these criteria evaluate some aspects of the sensors' performance in many fields, for some applications different criteria covering additional performance aspects may be more adequate [24]. 
To date, some personal exposure studies have supplied participants with MSUs that measured various air pollutants of exposure during daily routines (e.g., [2, 31]). However, exposure is affected by many factors, and thus the variance of the dose response function is typically high and dominates the attributed relative risks/hazard ratios results, regardless of sensors' accuracy [16, 17]. Therefore, one common practice for estimating individual exposure is to use a coarse scale $[5,32,25]$, rather than the sensors' actual measurement. Educational and citizen science applications typically aim at fostering informal and qualitative awareness. The measuring range in such applications is typically quantized into a binary scale, indicating the presence or absence of a pollutant. These scales and measures, although quantized, can still be used for relational comparison of air-pollution levels among different locations and times. This motivates the need for a more widely composed set of criteria to characterize the MSUs' actual (field) capabilities. Having such criteria allows for custom-made assessment of sensor's performance looking at properties that are important according to the task and application in hand.

This work presents a comprehensive Sensor Evaluation Toolkit (SET) for evaluating and comparing the AQMSUs' performance and its application on 25 sensors deployed in eight cities in Europe, as part of the CITI-SENSE project [25]. The R implementation of the SET is available on the first author's website.

\section{Material and Methods}

MSU evaluation can be executed either in a laboratory, with critical atmospheric ambient conditions measured and controlled, or in an open uncontrolled environment. The laboratory provides calibration against traceable reference standards. In an open, uncontrolled environment, the MSUs are placed in AQM stations and their measurements are compared against those acquired by AQM (reference) equipment. While the SET requires a reference device (dubbed REF) to evaluate the MSU measurements, it does not make any assertion on the nature of this reference equipment. The evaluation involves a comparison of two concentration time-series: one acquired by the MSU, $\left\{C_{k}^{M S U}\right\}$, and one obtained by the reference device, $\left\{C_{k}^{R E F}\right\}$. Both time-series should be of equal length, i.e. consist of $K$ measurements, with the measurement acquired more or less simultaneously.

The SET consists of eight performance measures, including the classic measures of RMSE and various correlations (described in Section 2.1). Four new measures, within the SET, are introduced: the presence measure that represents the sensor's availability over time (described in Section 2.2); the source-analysis, which depicts how accurately a sensor can identify and locate a source (detailed in Section 2.3); the match (detailed in Section 2.4) that evaluates the sensor's accuracy when the measured concentrations are transformed into generalized coarse scales; and the Lower Frequencies Energy Content (LFE), which 
measures the MSUs' ability to capture the temporal variability of the observed pollutant (Section 2.5). All measures are then combined into an Integrated Performance Index (IPI) (Section 2.6).

\subsection{Root Mean Squared Error and Correlation Coefficients}

The Root Mean Squared Error (RMSE) and the Pearson correlation measures are often used to evaluate MSUs' performance $[8,11,21,28,29]$. However, these measures apply specific assumptions on the errors and their distributions. RMSE measures the total bias (deviation) between two time series, and is often used to evaluate MSU errors [21, 28, 11]. While the RMSE is an excellent general-purpose error metric for numerical deviations, it severely amplifies and disproportionally accounts for large errors. Thus, if two signals have the same values but a small abrupt large deviation the inter-unit RMSE will be large.

Correlation coefficients are often used for evaluating the similarity between two time series, usually in complement to the RMSE $[21,11,28]$. Correlation coefficients are robust to abrupt, large deviations and are bounded between $[-1,1]$, a property which will be exploited in our aggregation process (see Section 2.6). Typically, the correlation of the tested device with a reference is reported with the Pearson correlation coefficient (e.g., $[8,21,11,28,29])$. However, the commonly used Pearson correlation coefficient, $\rho$, measures how well AQM measurements can be represented by the MSU records using a linear function. This measure is adequate if both the AQM and the MSU are in their linear sensitivity range. Ambient pollutant levels are often below the linear range of the MSUs [26, 27, 30, 28]. Therefore, the SET includes also the Kendall- $\tau[33,34]$ and the Spearman rank correlation coefficients, S, [35], which do not assume normality of the underlying variables and perhaps more importantly, are more sensitive to monotonic but non-linear relationships. A real-life example of using the differently defined correlation coefficients is given in Section S1 of the supplementary information. The example presents seven NO MSUs (CitiSense Leo Model, Ateknea Solutions Catalonia, Spain), which are evaluated against a reference AQM for 20 days. While the Pearson and Kendall- $\tau$ coefficients are relatively low, and would have rendered the sensor as inadequate, the Spearman coefficient shows that the sensor is suitable for NO measurements, given linearity is not considered. This phenomenon is due to the low NO ambient levels out of the linear response range of the MSUs [36]. Thus, the multiple evaluation criteria allow to better characterize MSUs' suitability to different applications. 
137 Each sensor's time series may contain missing values. This may result from the sensor malfunctioning or from communication errors. The presence measure accounts for the sensor's or system's availability of a measurement at a given time, and reports the fraction of the acquired measurements of all theoretically possible. The presence of an MSUs is a significant factor in evaluating any outdoor measuring device. For calculating, for example, averages during a given time interval, a minimum data availability is required to ensure representativity. Limited presence always brings about the question of representativity of the measurements for a given environment, and may indicate high maintenance costs. With that, sensor's presence is completely omitted from the RMSE and correlation evaluation criteria. Standard AQM stations are bounded to standards, connected to the power grid and are placed in dedicated containers, where only the inlets are exposed to outside and weather conditions. Thus, measuring equipment presence is typically a non-issue for AQMs. When it comes to MSUs, presence is often a major hurdle. This is why this measure has a larger significance when evaluating MSUs.

\subsection{Source Analysis}

For many applications such as source apportionment $[37,38]$ or dispersion models, especially Lagrangian models [39, 40], the source location is crucial. Bivariate polar plots, which represent how the concentration of a pollutant varies with the wind direction and speed at the receptor, have proved to be a useful tool for identifying and understanding pollution sources [37, 38, 39, 40, 21]. This representation manifests the directional dependence of different sources, particularly when more than one monitoring site is available, making source-analysis ideal for WDESN applications. The source location analysis within the SET aims at evaluating how accurate the MSU is in identifying and locating sources. i.e., it assesses the ability of the device to react to changes in observations within a time interval that corresponds to wind direction change, and to be sensitive enough to measure associated changes in concentrations. This is achieved through the calculation of the two-dimensional Pearson correlation between polar plots obtained from the reference device and the MSU, treating both as twodimensional matrix arrays [41]. For generating the polar plots, time-matched measurements of the wind and the pollutant must be available. This information is typically obtained either from the AQM station (given it measures these meteorological parameters) or by an externally collocated wind vane. Section S2 of the Supplementary material presents an example of a set of two $\mathrm{PM}_{2.5}$ MSUs evaluated against an AQM station. While all other performance criteria of the two sensors are relatively similar, the source analysis 
incorrectly so it has an obscure observation. Thus, a low source analysis score may allow us to find the problem and rectify it.

\subsection{Match Score}

Integrated AQ measures, such as the Air Quality Index (AQI) [32], are often used to convey the general notion of severity of air-quality to the public, ranking observations according to a chosen scheme. Such measures may also be used when the research question does not require precise measurements but rather a more general interpretation, such as general risk estimation [5, 32] and citizen science [24]. When applying such an AQ grading scheme, neither the RMSE nor the coefficient of determination represent well the sensor's performance, as they penalize small pertubations in the measurements. Thus, if an MSU deviates, due to its inaccuracy, from a reference device and if its deviations are randomly distributed around the reference value, these two measures will report poor performance. The match score overcomes this limitation and its calculation is as follows:

1. Set COUNT $=0$

2. Compute the dynamic range for $\left\{c_{t}^{M S U}\right\}$ and for $\left\{c_{t}^{R E F}\right\}$, i.e., $\left[\min \left\{c_{t}^{M S U}\right\}, \max \left\{c_{t}^{M S U}\right\}\right]$ and $\left[\min \left(\left\{c_{t}^{R E F}\right\}\right), \max \left(\left\{c_{t}^{R E F}\right\}\right)\right]$ for all $t \in T$.

3. For $d=1$ to $\mathrm{D}$ do:

a. Divide MSU's dynamic range into $d$ equal bins and label them 1 through $d$.

Divide REF's dynamic range into $d$ equal bins and label them 1 through $d$.

b. For each pair of measurements $\left\{c_{t}^{\mathrm{MSU}}, \mathrm{c}_{\mathrm{t}}^{\mathrm{REF}}\right\}, \mathrm{t} \in \mathrm{T}$ :

If $c_{t}^{\mathrm{MSU}}$ and $\mathrm{c}_{\mathrm{t}}^{\mathrm{REF}}$ belong to the bins with the same label $\rightarrow$ COUNT $=$ COUNT +1 ;

4. Compute: Match Score $=\frac{1}{D \cdot T} \cdot \operatorname{COUNT}$

Algorithm 1 - Match Score

As can be seen, the match score is the proportion of agreement among strata for increasing amount of sub-partitions between the reference and the MSU measurements. If we would like to compare the different MSUs, the number of maximum sub-partitions, $D$, should be predetermined and be kept constant throughout the analyses. Its value should be the highest number that still has at least one set of measurements $c_{t}^{\mathrm{MSU}}$ and $\mathrm{c}_{\mathrm{t}}^{\mathrm{REF}}$ that belong to the same bin. In our analyses, after several preliminary runs, $D$ was set to 10 . 
224

\subsection{Lower Frequencies Energy (LFE)}

The signal Lower Frequency Energy, dubbed LFE, is a characteristic of the signal rather than a comparative measure with respect to a reference device. Let us assume that $p(t)$ is a continuous signal that represents the true ambient level of a specific pollutant in a specific location. Both the MSU and the AQM average $p(t)$ over a small sliding temporal-window, $h(t)$, of a size $\Delta t$, obtaining $\bar{p}(t)$, and sample it to obtain the aforementioned discrete time series $\left\{C_{k}^{M S U}\right\}$ and $\left\{C_{k}^{R E F}\right\}$. Formally, the averaging is described by a convolution integral:

$$
\bar{p}(t)=\int_{-\infty}^{\infty} p(\tau) h(t-\tau) d \tau
$$

Equation 1

Let $\omega$ be the Fourier Transform domain coefficients. Applying the Fourier Transform on $p(t)$ and $h(t)$ (obtaining $P(\omega)$ and $H(\omega)$ ) respectively and the convolution theorem [47], the Fourier representation of $\bar{p}(t), \bar{P}(\omega)$, is given by:

$$
\bar{P}(\omega)=P(\omega) \cdot H(\omega) \quad \text { Equation } 2
$$

The Fourier Transform's amplitude of $h(t)$ is presented in Figure 1 for four different window sizes: averaging over 5, 15, 30 and 60 minutes. It can be seen that at zero $H(\omega)$ receives a value of one and its value decreases as $\omega$ (in absolute value) increases. Considering Equation 2, the sampling process suppresses higher frequencies, i.e, it applies low-pass filter on the observed signal. Thus, larger windowsizes in the signal domain, i.e. larger $\Delta t$, represent narrower filters in the frequency domain.

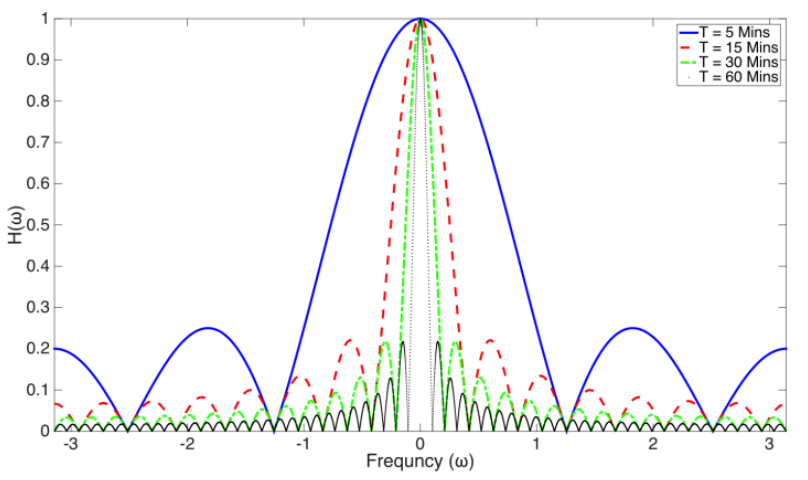

Figure 1 - Fourier Transform of $h(t)$ averaging over 5 min period, i.e. $\Delta t=5$ (solid blue), $\Delta t=15 \mathrm{~min}$ (dashed red); $\Delta t=30 \mathrm{~min}$ (dotdash green); and $\Delta t=60 \mathrm{~min}$ (dotted black).

If the observed pollutant signal changes rapidly, its higher-frequency coefficients will assume higher values. Considering Equation 2, these values would be diminished in the acquired signal if they are 
multiplied by a narrow $H(\omega)$, i.e. averaged over a large temporal-window. A real-life example is given in Section S3 in the supplementary material.

The signal's energy is a characteristic used in signal processing and is given by:

$$
E=\int_{-\infty}^{\infty}|p(t)|^{2} d t
$$

Equation 3

Following the Parseval's theorem [48], the energy of a signal is equal to the energy of its Fourier transform:

$$
E=\int_{-\infty}^{\infty}|P(\omega)|^{2} d \omega
$$

Equation 4

Hence, the function $|P(\omega)|^{2}$ represents the energy distribution in the frequency domain. The smaller the energy portion in the higher frequencies, the better the sensor can capture the signal's temporal variability. Thus, the portion of the signal's energy in the lower frequencies, i.e. the Lower Frequencies Energy (LFE), can be used for evaluating the sensor's capability to capture the temporal variability of the pollutant. After discrete sampling that accounts for the $\mathrm{K}$ samples in the pollution time series Equation 4 becomes:

$$
E=\sum_{\omega=1}^{K}|P(\omega)|^{2},
$$

Equation 5

and the LFE measure is computed as:

$$
L F E=1-\frac{\sum_{\omega=1}^{K}\left(\omega \cdot|P(\omega)|^{2}\right)}{E \cdot \frac{K(K-1)}{2}}
$$

Equation 6

where $E$ is given by Equation 5 .

The maximum value that LFE can obtain is 1 , which represents the case where all the information is within the first frequency coefficient, i.e., all frequency coefficients, but the first one, are zero.

MSUs are typically self-contained units with their own power supply and transmission modules. Typically, data acquisition and transmission times are set such that operational energy consumption (for data acquisition and transmission) is minimized. Consequentially, their sampling interval, $\Delta t$, may be long, i.e., low sampling rate, which corresponds to narrow low-pass filtering. Therefore, while applicable to AQM and standard laboratory equipment, a measure of spectral distribution is especially important to MSUs working under power consumption constraints.

\subsection{Integrated Performance Index (IPI)}

The SET consists of eight different performance measures accounting for different aspects of signal acquisition. Different combinations of these measures can be used in order to evaluate the sensor performance, depends on the specific application. In order to integrate the various measures, it is 
important that they all share the same scale. This is inherent for the SET as all measures span between [0,

263

264

265

266

267

268

269

270

\section{1}

272

273

274

275

276

277

278

279

280

281

282

283

284

285

286

287

288

289

290 $1]$.

Integration of several measures into an overall evaluation measure can be done either by addition or multiplication of all measures together. The former facilitates an aggregation scheme that can account for different weights for the different measures by introducing weight coefficients, $\vec{\alpha}$. Given $\vec{\alpha}$, and $\vec{m}$ the measures vector for a given sensor (RMSE, correlations, presence, source analysis, match and LFE) and the time series $\left\{C_{k}^{M S U}\right\}$ and $\left\{C_{k}^{R E F}\right\}$ acquired by the sensor and a reference device respectively, the IPI is given by:

$$
I P I^{M S U}=\sum_{i} \alpha_{i} m_{i}\left(\left\{C_{k}^{M S U}\right\},\left\{C_{k}^{R E F}\right\}\right)
$$

Equation 7

\subsection{SET Implementation and Application}

For demonstrating the method and its capabilities, the SET was implemented in R. For evaluation, the MSUs are compared against a reference device. This device can be either AQM or laboratory calibrated equipment. Both the MSU and the reference device must measure the same physical phenomenon (e.g., ambient levels of a specific pollutant, temperature or relative humidity). The same physical phenomenon can be measured when the sensors are collocated [21, 11, 28] or when the observed phenomenon is uniform in all measuring points $[21,49]$. When no AQM nor reference devices are available the same analysis can be done with respect to the average signal of the entire sensory network in a given region [21]. Here we demonstrate the SET for collocated sensors with AQM stations.

For demonstrating the capabilities and richness of the suggested evaluation toolkit, twenty-five MSU pods (Geotech AQMesh, UK [50]) were placed near ten different AQM stations in eight cities in Europe, as part of the European Union $7^{\text {th }}$ framework program (FP7) CITI-SENSE project [25]. The full deployment, acquiring data for about three months at each location, is detailed in Section S4 of the supplementary material. Each AQMesh unit was equipped with five environmental sensors: $\mathrm{NO}, \mathrm{NO}_{2}, \mathrm{O}_{3}$, atmospheric pressure $(A P)$, and relative humidity $(\mathrm{RH})$. Some of the AQMEsh pods included also OPC PM sensor. Additionally, the AQMesh measured the unit's (internal) temperature (Temp). The specific AQM parameters (location, height above ground level (AGL) and above sea level (ASL)) are detailed in Section S4 of the supplementary information. The average temperature and the averages of all measured pollutants are provided in Table 1 alongside their SET performance. The latter is color coded to represent low to high SET values in a red-to-green color scale. 
291

292

293

294

295

296

297

298

299

300

301

302

303

304

305

306

307

308

309

310

311

312

313

314

315

316

317

318

319

320

321

In order to compare the AQM and the MSU measurements, the time resolution of both should be the same. If that is not the case, the finer time resolution time series has been aggregated so it fits the coarser resolution. The MSU time-series were acquired at a 15-min resolution, while the AQM time-series had a 30 (or 60) -min resolution. Hence, MSU measurements were averaged (without overlap) to produce a time-series that corresponds to the AQM temporal resolution.

\section{Results and Discussion}

\subsection{Overview}

Table 1 depicts the average values of the measured environmental parameters, showing that the MSUs' meteorological measurements are more accurate than those of pollutant concentrations. The AP, (pod internal) Temp and RH sensors have, on average, an Integrated Performance Index (IPI) of 0.975, 0.875 and 0.851, respectively. Among the pollutants, NO sensors had the highest IPI, with an average of 0.705 . $\mathrm{O}_{3}, \mathrm{CO}$ and $\mathrm{NO}_{2}$ obtained IPIs of $0.664,0.609$ and 0.578 , respectively.

The utilization of the SET for evaluating MSU performance is well demonstrated in Table 1. Sensor 143, which presents lower IPI values for all measured environmental parameters, may have experienced a systematic error. This may result from incorrect placement of the sensor or malfunction of hardware. Sensor GAP 4 presents low IPI for RH. The average RH value that this sensor reported was $106.4 \%$. This clearly suggests that the sensor is faulty or overly-offset for this parameter. Sensor 118 presented low IPI for $\mathrm{CO}$ and NO while their average concentrations were much higher than those measured by the AQM and other collocated MSUs. All these measurements were removed from the following analysis.

The richness offered by the IPI is presented in Table 2, through the breakdown of the IPI measure into its components (Mean (M), Match score, RMSE, Pearson $\rho$, Kendall $\tau$ and Spearman (S) correlation coefficients; Source-analysis score, Presence (Pres.) and Lower Frequencies Energy (LFE) content) for two sensors - \#118 NO and \#130 Temp sensors. For both sensors the LFE measure is high, suggesting that the changes in the observed signal are slower than the sampling rate. The \#118 NO sensor presents extremelylow correlation values, while its match score is high. Thus, while this specific sensor would grade poorly using the traditional evaluation tools (correlation and RMSE), it would be more than sufficient for many of the aforementioned applications, such as citizen science and exposure estimations. The Temp sensor of pod \#130 also presents interesting behavior. Its Match as well as its correlation coefficients are reasonable, but its RMSE score is very low. This suggests that while the sensor does not represent the true ambient levels, i.e., it has some bias, it does represent the signal's behavior (i.e., good correlations). Indeed, this was the case, as explained in section 3.3. Therefore we conclude that the different 
components of the IPI measure do give a better understanding of the sensor performance and its suitability for different applications.

\subsection{Temperature Impact on the Measurements}

325 Ambient temperature has been pointed-out as a major factor affecting sensor performance [21, 11, 28, 326 29]. Here we examine this using the IPI. Figure 2 shows the average IPI of all 25 MSUs for all seven 327 measured parameters, as a function of the average temperature that was measured by the AQM station 328 throughout the campaign. The temperature effect is evaluated over 175 measurements. Each of these 329175 measurements consists of more than three months' worth of data. Thus, the temperature evaluation 330 is based on a large dataset. No apparent trend is observed, suggesting that the MSUs manage to 331 compensate for any temperature impact on the measurements. Previously reported temperature effects 332 on $A Q$ measurements may be attributed to higher pollution levels in winter time (due to higher pollution 333 source strength and pollution accumulation during periods with temperature inversions [51, 52]). This is 334 because while temperature was not found to affect sensors' performance, the measured ambient levels, 335 as is shown later, do have an effect, where the sensors performs better in higher pollution levels. Next, 336 we analyze the IPI specifically for each measured parameter. 


\begin{tabular}{|c|c|c|c|c|c|}
\hline 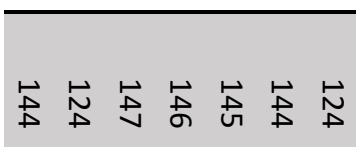 & $\underset{\omega}{\vec{\omega}} \underset{\infty}{\stackrel{心}{\infty}} \underset{\sim}{\vec{\sim}}$ & 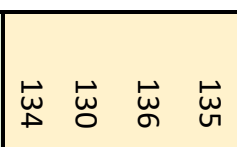 & 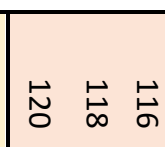 & 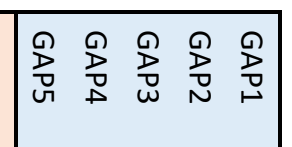 & $\stackrel{\subseteq}{\stackrel{亏}{F}}$ \\
\hline 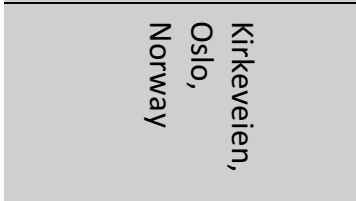 & 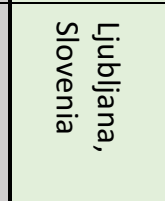 & 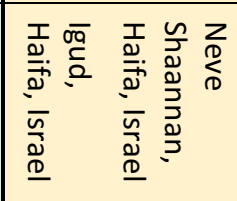 & 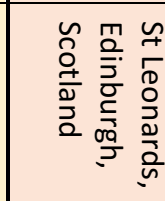 & 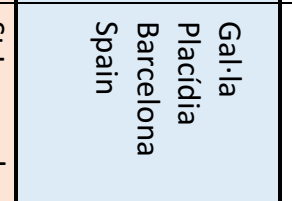 & $\begin{array}{l}\overline{0} \\
\stackrel{0}{0} \\
\frac{0}{3}\end{array}$ \\
\hline 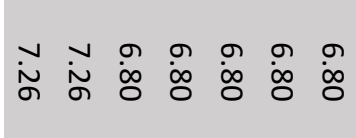 & $\begin{array}{lll}\vec{N} & \vec{N} & \vec{N} \\
\hat{\tilde{N}} & \dot{\hat{\sigma}} & \hat{\sigma}\end{array}$ & $\begin{array}{llll}\vec{\omega} & \vec{N} & \vec{N} & \vec{N} \\
\dot{\omega} & \dot{\omega} & \dot{0} & \dot{0} \\
\omega & i & i\end{array}$ & ${ }^{\prime}{ }_{\omega}$ & $\left|\begin{array}{ccccc}\tilde{w} & \tilde{\omega} & \tilde{\omega} & \tilde{\omega} & \tilde{\omega} \\
\tilde{N} & \tilde{N} & \dot{N} & \tilde{N} & \dot{N}\end{array}\right|$ & ) \\
\hline 晏㤐 总 & $\mid \begin{array}{lll}\infty & 0 & 0 \\
0 & \infty & 0\end{array}$ & 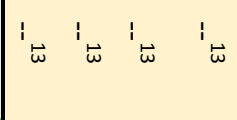 & '心 & 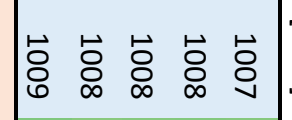 & \multirow{2}{*}{ 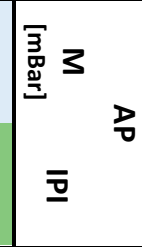 } \\
\hline 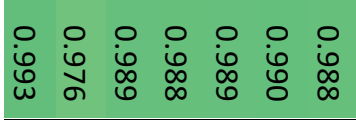 & $\left|\begin{array}{lll}i & 0 & 0 \\
\dot{b} & 0 & 0 \\
+ & 0 & 0 \\
+ & 0 & 0\end{array}\right|$ & 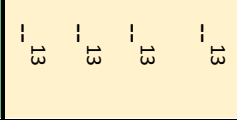 & 's & 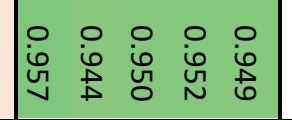 & \\
\hline 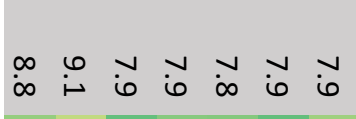 & 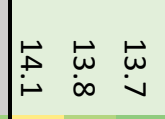 & 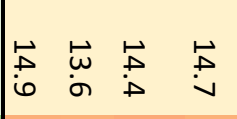 & ${ }^{\prime}{ }_{\omega}$ & 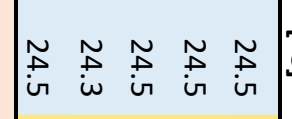 & \multirow{2}{*}{ 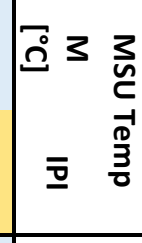 } \\
\hline 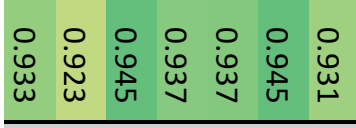 & $\begin{array}{lll}\circ & 0 & 0 \\
\dot{0} & \dot{0} & 0 \\
\infty & \tilde{L} & 4 \\
\end{array}$ & 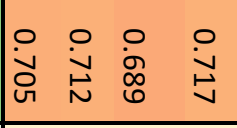 & ${ }_{\omega}$ & 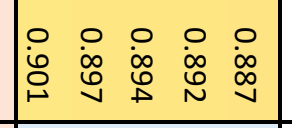 & \\
\hline 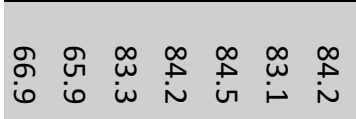 & 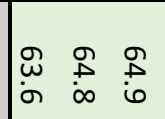 & 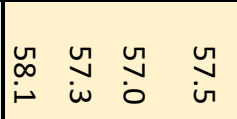 & ${ }^{\prime}$ & 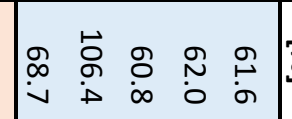 & \multirow{2}{*}{ 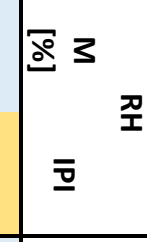 } \\
\hline 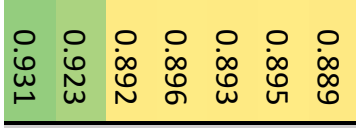 & 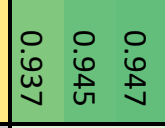 & 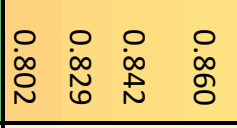 & ${ }^{\prime}{ }_{\omega}$ & 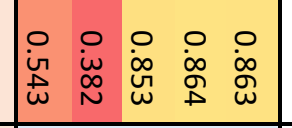 & \\
\hline 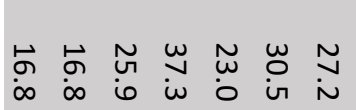 & 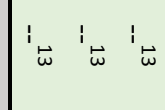 & $\underset{i}{i} \underset{i}{\sim} \underset{\omega}{w}$ & 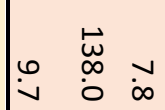 & 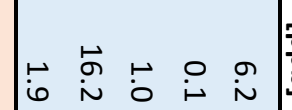 & \multirow{2}{*}{ 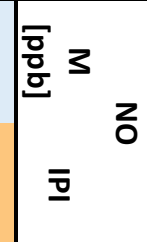 } \\
\hline 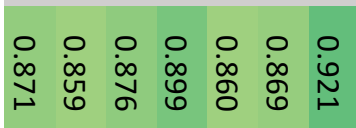 & 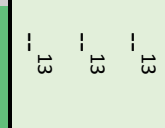 & 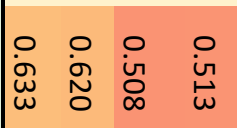 & 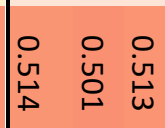 & 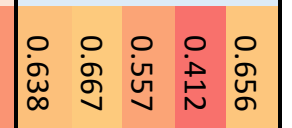 & \\
\hline 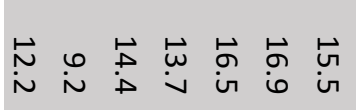 & $\sigma \stackrel{w}{\stackrel{0}{O}} \sim$ & 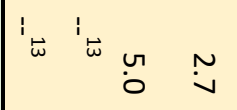 & i & 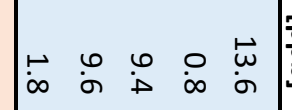 & \multirow{2}{*}{ 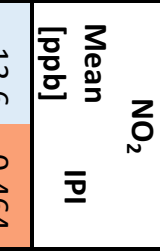 } \\
\hline 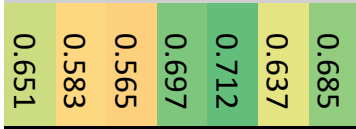 & 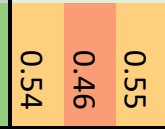 & 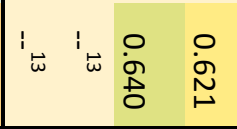 & $\begin{array}{lll}0 & 0 & 0 \\
\dot{\vec{t}} & \dot{\omega} & 0 \\
\dot{\omega} & \stackrel{0}{0}\end{array}$ & 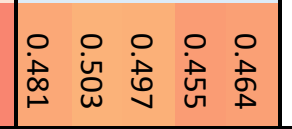 & \\
\hline 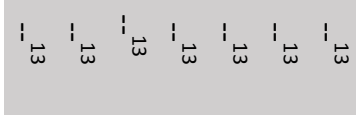 & $\mid \begin{array}{ccc} & \overrightarrow{0} & \\
0 & 0 \\
0 & 0 & 0 \\
0 & \infty & \infty\end{array}$ & 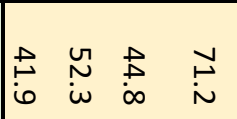 & 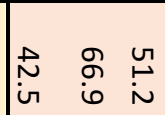 & 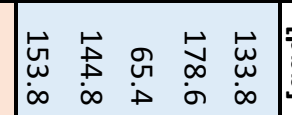 & \multirow{2}{*}{ 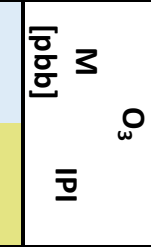 } \\
\hline 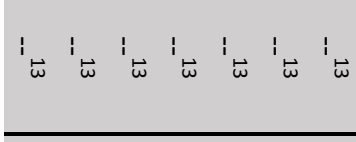 & 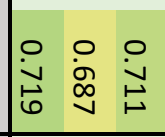 & 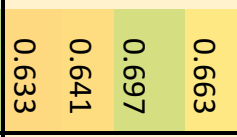 & 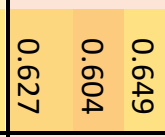 & 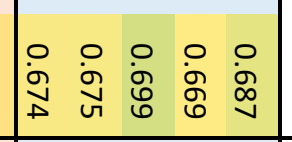 & \\
\hline 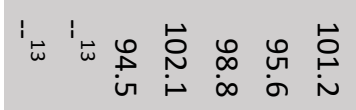 & 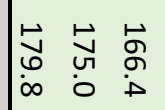 & 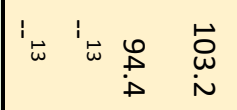 & 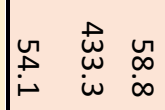 & 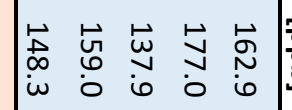 & \multirow{2}{*}{ 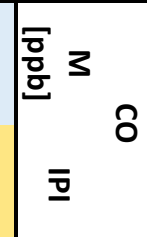 } \\
\hline 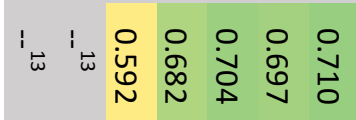 & 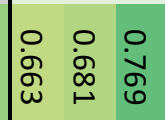 & 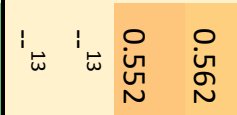 & 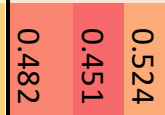 & 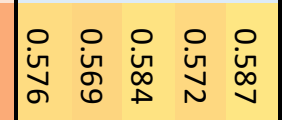 & \\
\hline
\end{tabular}




\begin{tabular}{|c|c|c|c|c|}
\hline बू. & 点 & $\underset{N}{N} \underset{N}{N}$ & $\stackrel{\text { 完 }}{\stackrel{9}{口}}$ & 点 \\
\hline$\Xi$ & 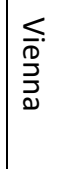 & 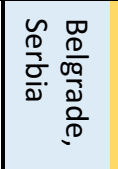 & 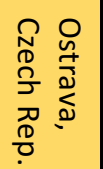 & 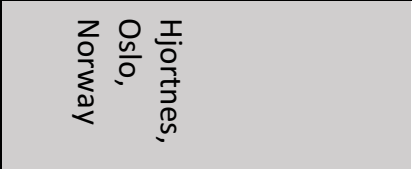 \\
\hline & ب) & 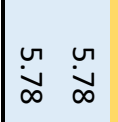 & ச் & 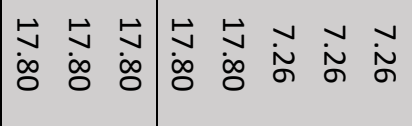 \\
\hline & & $\begin{array}{ll}\vec{\circ} & \vec{\circ} \\
\infty & 0\end{array}$ & 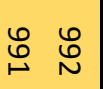 & 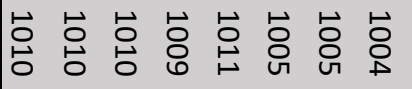 \\
\hline $\begin{array}{l}0 \\
\dot{0} \\
\text { w } \\
w\end{array}$ & & 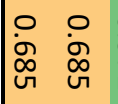 & 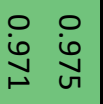 & 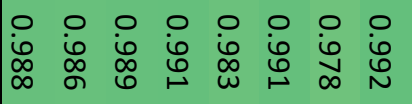 \\
\hline & $\stackrel{\vec{m}}{i-}$ & $\ddot{v} \quad \stackrel{v}{v}$ & $\vec{\sigma} \dot{\sigma}$ & 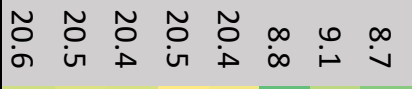 \\
\hline 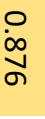 & $\mid \begin{array}{l}0 \\
\dot{A} \\
\omega\end{array}$ & $\begin{array}{ll}0 & 0 \\
0 & \infty \\
\infty & \infty \\
D & \infty \\
0 & \sim\end{array}$ & $\begin{array}{ll}0 & 0 \\
0 & 0 \\
0 & 0 \\
0 & 0 \\
0\end{array}$ & 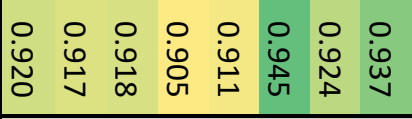 \\
\hline & 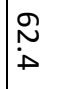 & $\mid \begin{array}{ll}\infty & \infty \\
\stackrel{\leftrightarrow}{+} & \stackrel{\infty}{\infty}\end{array}$ & $\begin{array}{lll}\infty & \infty \\
0 & \infty \\
\infty & 0 & \text { ir }\end{array}$ & 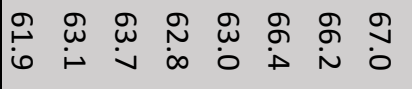 \\
\hline $\begin{array}{l}0 \\
\infty \\
\infty \\
\infty \\
\infty\end{array}$ & 品 & $\mid \begin{array}{ll}0 & 0 \\
0 & 0 \\
0 & 0 \\
\omega & 0\end{array}$ & $\begin{array}{ll}0 & 0 \\
0 & 0 \\
0 & 0 \\
i & \stackrel{5}{⺊}\end{array}$ & 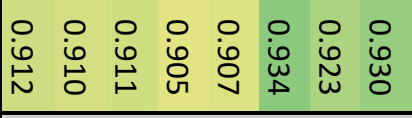 \\
\hline & $\underset{\dot{\sim}}{\dot{\omega}}$ & $\mid \begin{array}{ll}\infty & 0 \\
\infty & \stackrel{0}{v}\end{array}$ & ${ }^{\prime}{ }_{\omega}$ & 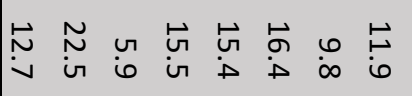 \\
\hline ¿ٕ & $\mid \begin{array}{l}0 \\
\dot{w} \\
\infty \\
v\end{array}$ & 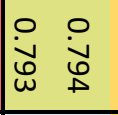 & 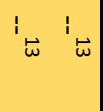 & 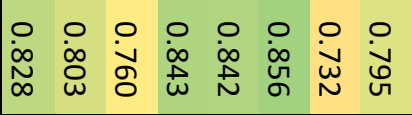 \\
\hline & vi & $\mid \begin{array}{ll}\vec{f} & N \\
\dot{\omega} & \text { ir }\end{array}$ & ${ }^{\prime} \mathrm{\omega}$ & 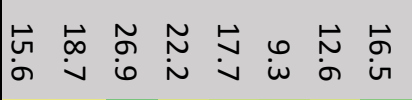 \\
\hline ì & $\mid \begin{array}{l}\infty \\
\dot{w} \\
\infty \\
\infty \\
\infty\end{array}$ & $\begin{array}{ll}\circ \\
\text { in } \\
\text { Un }\end{array}$ & 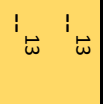 & 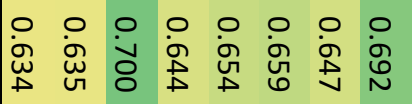 \\
\hline & 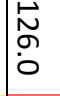 & $\mid \begin{array}{ll}0 & w \\
0 & w \\
0 & \infty\end{array}$ & 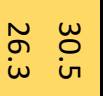 & 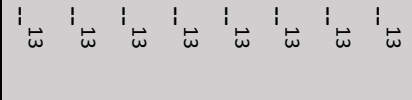 \\
\hline 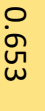 & 唄 & $\mid \begin{array}{ll}0 & 0 \\
i & i \\
\omega & i \\
v & \infty \\
\end{array}$ & 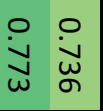 & 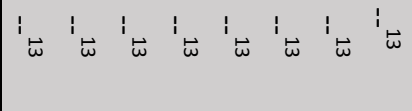 \\
\hline & ${ }^{\prime}{ }_{\omega}$ & 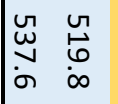 & ${ }^{\prime}{ }_{\overparen{\omega}}{ }^{\prime}{ }_{\omega}$ & 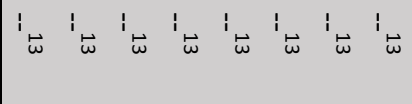 \\
\hline : & ${ }^{\prime} \stackrel{\omega}{\omega}$ & 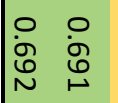 & ${ }^{i}{ }_{\omega}{ }{ }^{\omega}{ }_{\omega}$ & 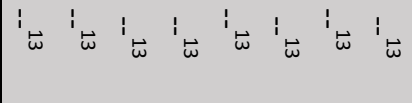 \\
\hline
\end{tabular}


Table 2 - IPI breakdown - Mean ambient level (M); Match score; Root Mean Squared Error (RMSE); Pearson $\rho$ correlation coefficient; Kendall $\tau$ correlation coefficient; Spearman (S) correlation coefficient; Source analysis; Presence (Pres.); Low Frequencies Energy (LFE) content and the integrated Air Quality Index (IPI)

\begin{tabular}{|l|l|l|l|l|l|l|l|l|l|l|}
\hline Sensor & $\mathbf{M}$ & Match & RMSE & $\boldsymbol{\rho}$ & $\boldsymbol{\tau}$ & $\mathbf{S}$ & Source & Pres. & LFE & IPI \\
\hline $\mathbf{1 1 8}$ (NO) & 129.9 & $\mathbf{0 . 9 2 0}$ & 0.24 & 0.063 & 0.068 & 0.090 & $--^{14}$ & 0.732 & 0.976 & $\mathbf{0 . 5 1 9}$ \\
\hline $\mathbf{1 3 0}(\mathbf{T})$ & 13.63 & 0.462 & 0.003 & 0.679 & 0.538 & 0.712 & $--^{14}$ & 1 & 0.997 & $\mathbf{0 . 7 1 2}$ \\
\hline
\end{tabular}

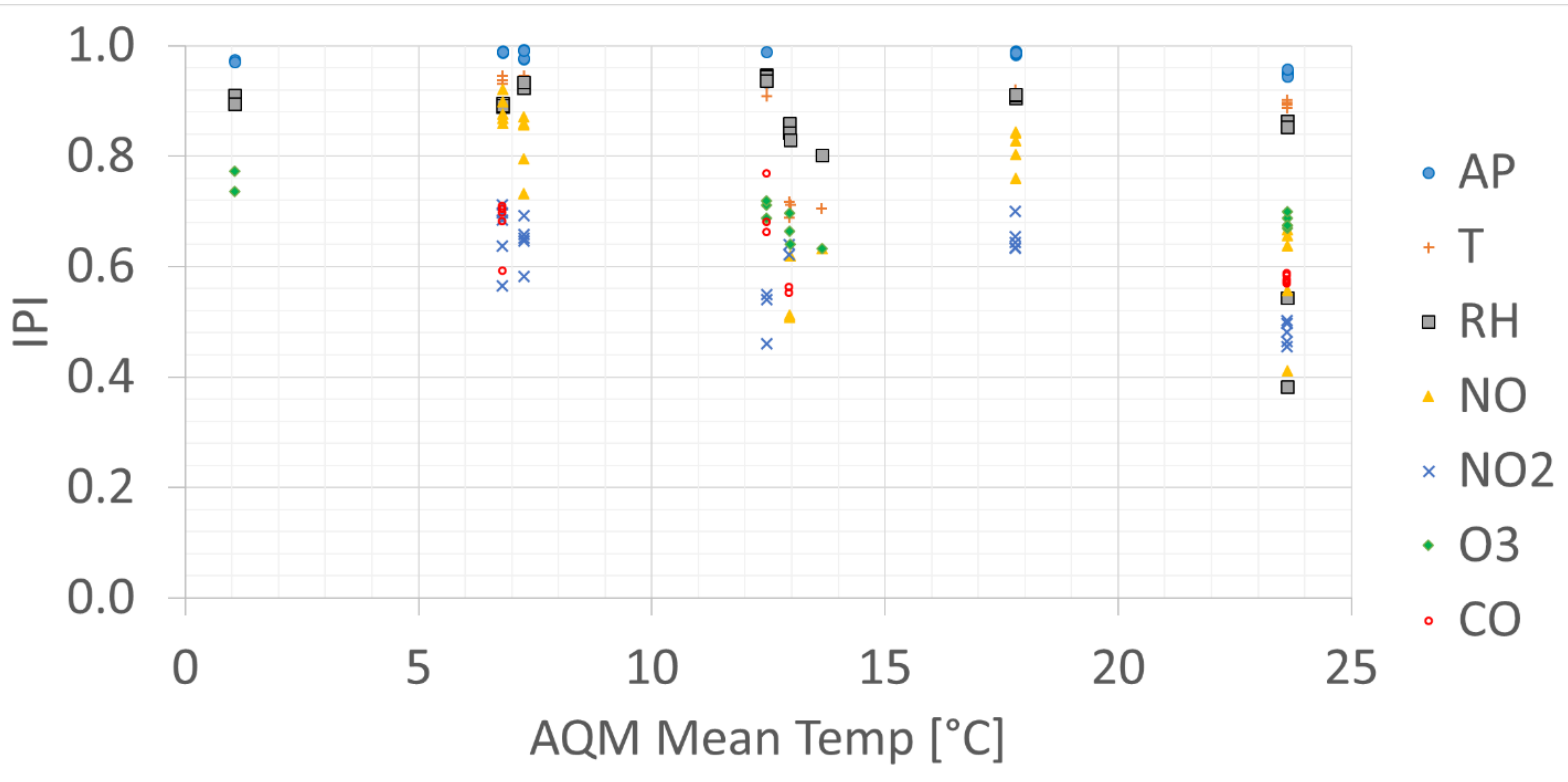

Figure 2 - IPI of the various measured parameters as a function of the ambient Temperature

\subsection{Meteorological Sensors}

Figure 3 presents the IPI for the Temp, AP and RH sensors for all MSUs, as a function of their average values. The first notion that arises from this presentation is that, in general, the sensors' IPI is indifferent to changes in the observed meteorological parameter. It is worthwhile mentioning that the batch of temperature sensors with lower IPI values (marked in circle in Figure 3a) were all obtained in the same station in Haifa, Israel. Further queries revealed that temperature records in this specific AQM were measured inside the monitoring station rather than outside, where the MSUs were located. This example demonstrates once again the use of the SET to point out sensing errors.

\footnotetext{
${ }^{14}$ The Source score could not be computed as no wind data was collected at this location.
} 


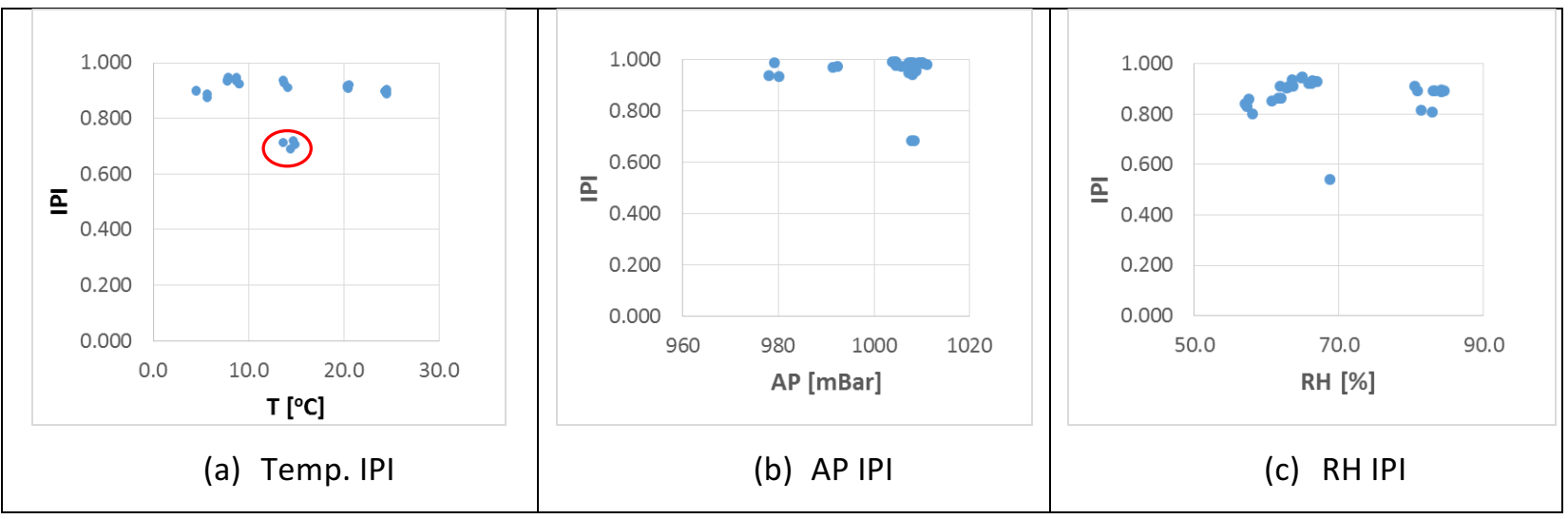

Figure 3 - IPI of a sensor as a function of its specific measured Meteorological Parameters - Temperature IPI (a), Air Pressure (AP) IPI (b), and Relative Humidity (RH) IPI (c)

\subsection{Gaseous Pollutants Sensors}

Figure 4 depicts pollutant specific sensor's IPI as a function of the average reading. Thus, the IPI of each pollutant's sensor, computed over the entire campaign, is plotted against the same pollutant's campaign average reading. It is evident from Figure 4 that the ambient level of the observed pollutant has a direct impact on the sensing quality. The lower the ambient pollutant level, the lower the IPI and the higher its variance for similar pollutant's ambient levels (i.e., the sensors presents lower reliability for lower pollutants ambient levels). Similar behavior was observed by Lerner et. al [29] and Moltchanov et. al [21]. Hence, the IPI suggests that the MSU sensors are more suitable for locations where the pollutant is known to be high. Means to extract the threshold are discussed next. As different pollutants have different ambient levels, it is important to note that the $x$-axes of all following figures present different scales.

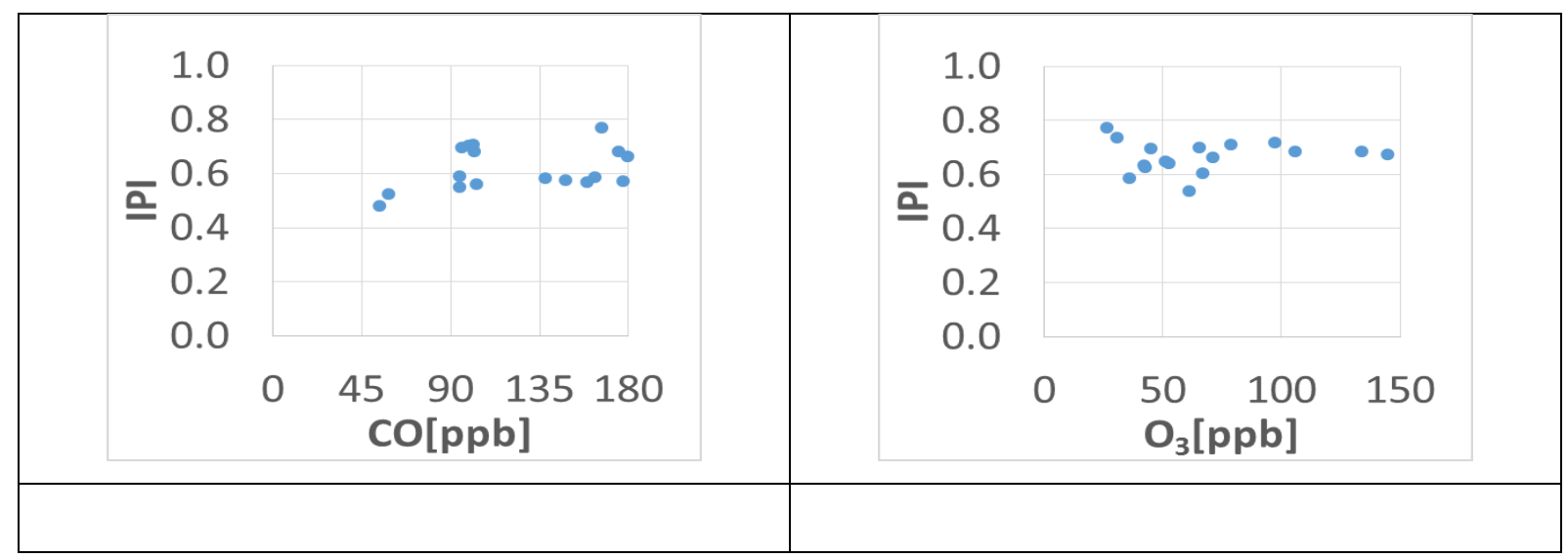




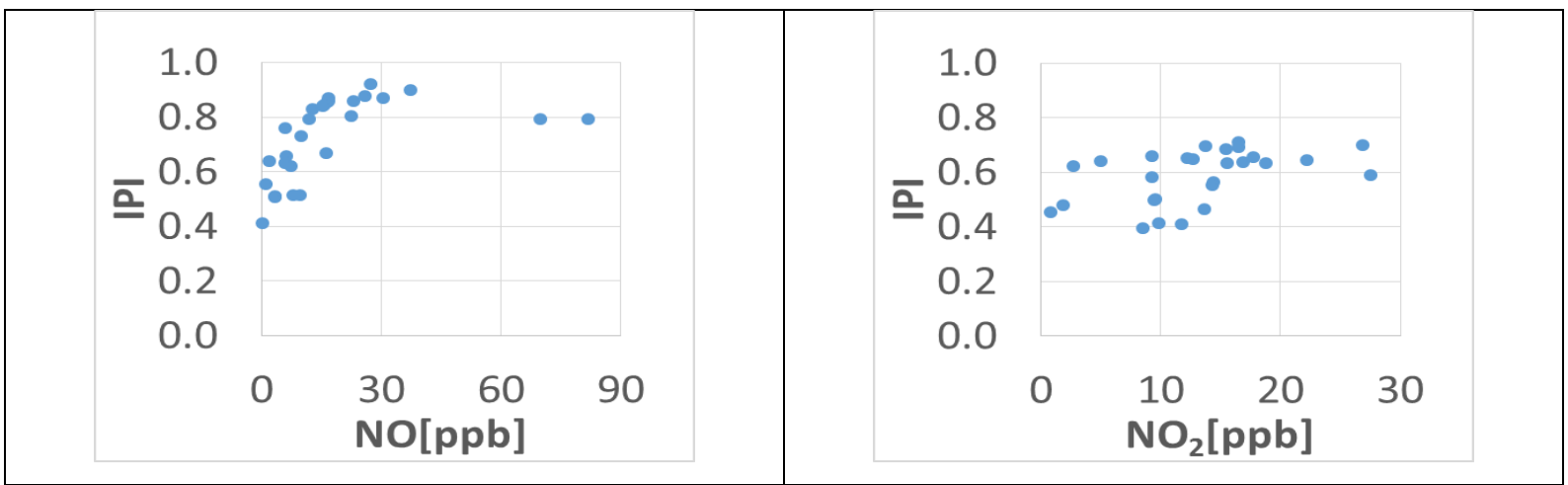

Figure 4 -IPI as a function of Pollutants' Recorded campaign average levels for each sensor on each node

The aforementioned IPI behavior as a function of the pollutant's ambient level is better observed when the IPI is computed based on a daily time series rather than using the entire campaign's time series. For example, Figure 5, depicts the daily IPI for $\mathrm{NO}_{2}(\mathrm{a})$ and $\mathrm{NO}$ (b) from measurements obtained in Kirkeveien, Oslo, by sensors \#124, \#144, \#145, \#146 and \#147 (see Section S4). One should determine the minimum ambient levels a sensor can measure where the IPI measure is high and the standard deviation is low (how high and how low is application dependent). Figures (c) and (d) depict the standard deviation of the IPI, computed for the associated IPIs of each decile of the pollution levels. It is evident that the standard deviation decreases as the IPI increases. Using the notions above, a sensible threshold for the sensors described for measuring NO2 and NO can be ambient levels that are higher than 30 ppb.

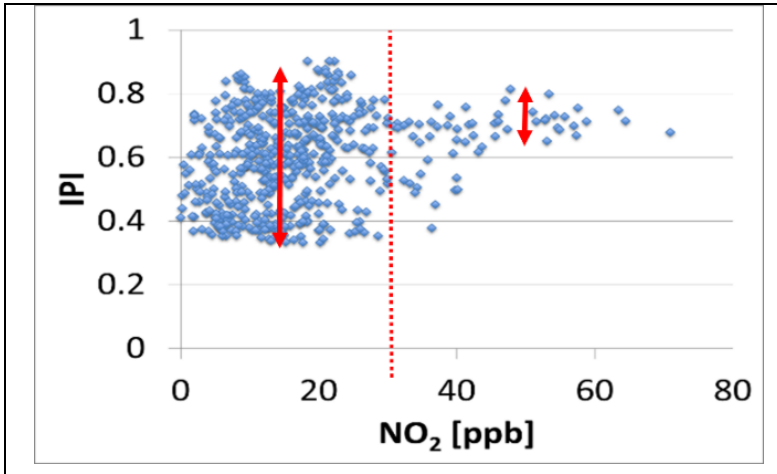

(a)

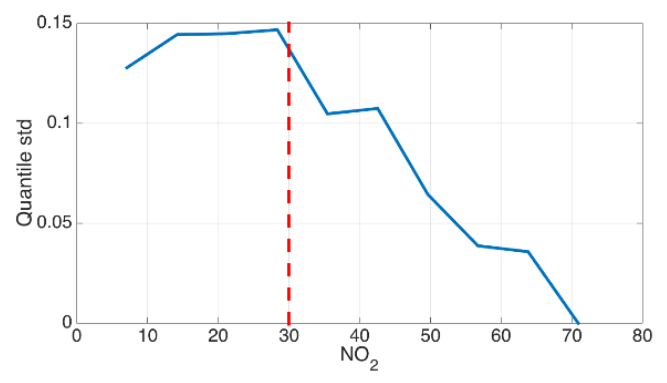

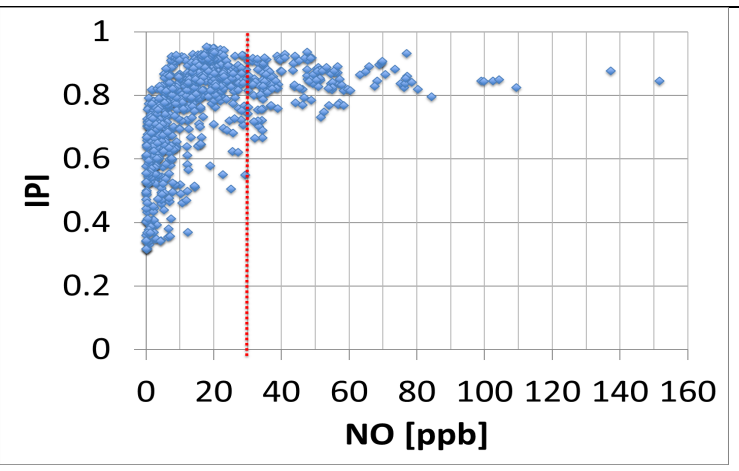

(b)

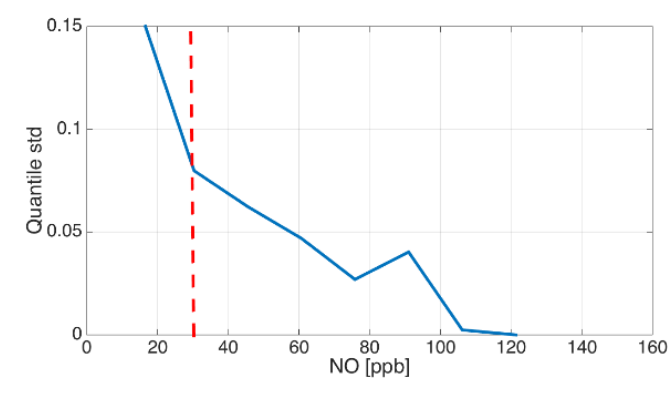


Figure 5 - IPI as a function of $\mathrm{NO}_{2}$ (a) and $\mathrm{NO}$ (b) Recorded Levels at Kirkeveien, Oslo (daily score). The standard deviation of the IPI computed for each pollution level decile are presented in Figures (c) and (d) for NO2 and NO respectively

Figure 6 demonstrates the utilization of the IPI for comparison between sensors and between different working conditions; The figure depicts the histograms of the $\mathrm{NO}$ and $\mathrm{NO}_{2}$ levels at Kirkeveien, Oslo, which are presented in Figure 5 (as time series). The notion above, of the effect of ambient levels on the sensors' performance, is evident in Figure 6, where a bimodal distribution of the IPI is well observed. The two models correspond to IPI scores above and below $30 \mathrm{ppb}$. Having the bimodal distributions' parameters inferred, one can study their relations. Formally, this can be done by the Kolmogorov-Smirnoff test for discrete variables $[53,54]$ comparing the best fitting distribution with the empirical distribution and test for significance.

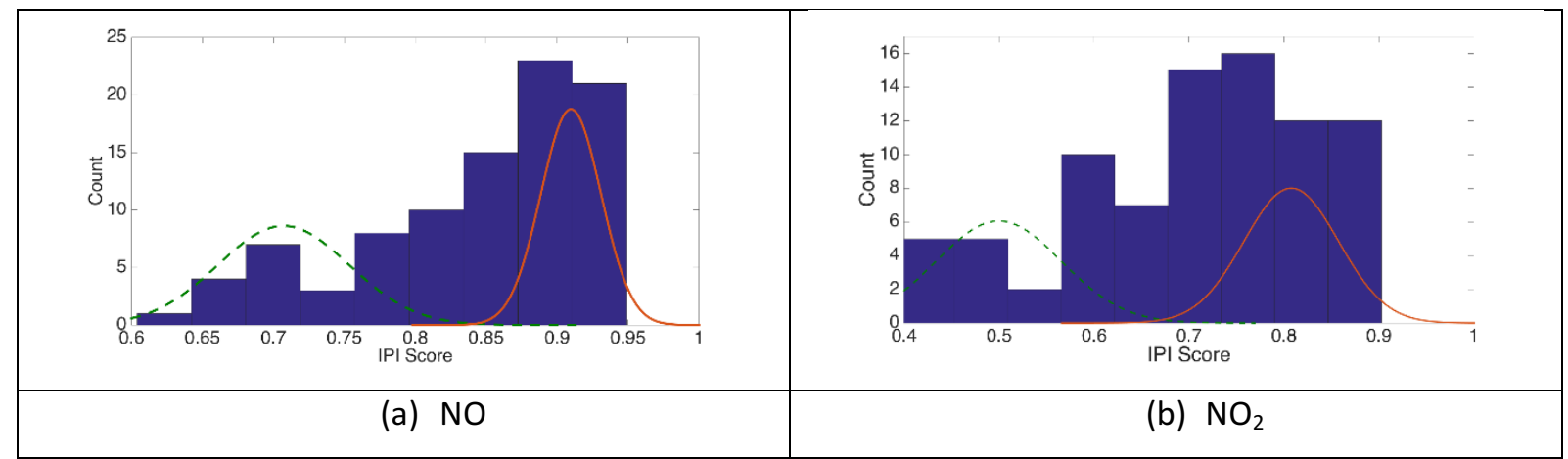

Figure 6- $\mathrm{NO}$ (a) and $\mathrm{NO}_{2}$ (b) IPI distribution functions measured at Kirkeveien, Oslo (daily score)

\subsection{Particulate Matter Sensors}

The SET criteria was applied to four different PM sensors, all collocated at the Igud AQM station (Haifa, Israel - see Table 1). The four sensors, two DC1700 Dylos (US) and two optical counters integrated on the GeoTech MSUs, were place next to the AQM's inlet between December $17^{\text {th }}$ and $24^{\text {th }}, 2015$. The data was recorded in 5 minutes' intervals. The four sensors measurements are displayed against AQM PM measurements (all measurements are in $\left[\mathrm{\mu gr}^{\mathrm{m}} / \mathrm{m}^{3}\right]$ ). 


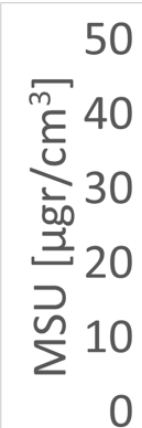

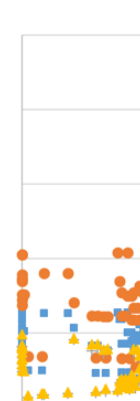

10<smiles>[Y5][C@H]1C[C@@H]2CC[C@H]12</smiles><smiles>C1CCCC1</smiles>

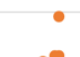
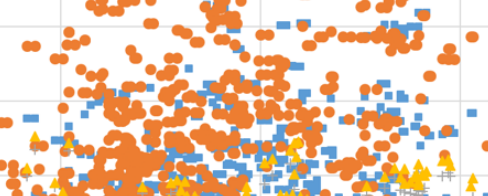

inis

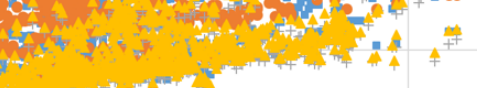

AQM $\left[\mu \mathrm{gr} / \mathrm{cm}^{3}\right]$

\section{- Geo703 • Geo706 + Dylos08 ^ Dylos09}

Figure 7-PM MSU measurements obtained between Dec. $17^{\text {th }}$ and $24^{\text {th }}$, 2015 plotted against collocated AQM station.

Table 3 shows the IPI breakdown for the PM sensors. The two types of sensors present different characteristics, while the GeoTech sensors present better RMSE, the Dylos ones have better match, correlations and eBalance. Thus, the SET is also capable to evaluate PM sensors and define better the suitability of a sensor to a specific application.

Table 3 - IPI breakdown of PM sensors

\begin{tabular}{|c|c|c|c|c|c|c|c|c|c|}
\hline & Mean & Match & RMSE & Pearson & Kendall & Spearman & Presence & eBalance & IPI \\
\hline Geo703 & 23.766 & 0.101 & 0.038 & 0.147 & 0.309 & 0.453 & 1.000 & 0.982 & 0.565 \\
\hline D706 & 26.926 & 0.119 & 0.023 & 0.259 & 0.284 & 0.421 & 1.000 & 0.993 & 0.579 \\
\hline Dylos08 & 139.894 & 0.311 & 0.134 & 0.560 & 0.468 & 0.639 & 1.000 & 0.997 & 0.693 \\
\hline Dylos09 & 152.258 & 0.312 & 0.147 & 0.570 & 0.474 & 0.647 & 1.000 & 0.997 & 0.695 \\
\hline
\end{tabular}

\section{Conclusions}

This paper presents a Sensor Evaluation Toolbox (SET) for evaluating AQ MSUs by a range of criteria. The rich evaluation provided by the suggested scheme allows for better assessment of sensors' performance in varied applications and environments. The SET consists of eight different assessment criteria: Root Mean Squared Error (RMSE), Pearson, Kandel and Spearman correlations, and four new performance measures for evaluating sensors' capability to: locate pollution sources; represent the pollution level on a coarse scale; capture the high temporal variability of the observed pollutant and their reliability. 
Application of the SET on measurements acquired by gaseous and PM MSUs deployed in eight cities across Europe showed that each of the eight measures provides an important and unique information on the sensor's performance assessing a rich spectrum of MSU capabilities. The result also demonstrate how the scheme can pinpoint systematic as well as sensor's specific faults. Further, we demonstrated that the Integrated Performance Index (IPI) can support a methodology for determining the sensors' performance, hence facilitating a true cross platform evaluation. The SET was implemented in R [55] and is available on the first author's website ${ }^{15}$.

\section{Acknowledgements}

We would like to acknowledge the AQM station managers for providing ambient air quality data, including the Haifa District Municipal Association for Environmental Protection (Israel); Xarxa de Vigilància i Previsió de la Contaminació Atmosfèrica de Catalunya (XVPCA), Direcció General de la Qualitat Ambiental, Departament de Territori i Sostenibilitat, Generalitat de Catalunya (Spain); the Slovenian Environment Agency (Slovenia); the Czech Hydrometeorological Institute (Czech Republic); Bureau Veritas, UK Ltd. (Edinburgh); the Serbian Environmental Protection Agency - SEPA (Serbia).

CITI-SENSE, initiated in October 2012, is a four year Collaborative Project partly funded by the EU FP7ENV-2012 under grant agreement 308524.

\section{References}

[1] International Agency for Research on Cancer (IARC), "Ambient Air Pollution," in IARC Meeting Monographs, Lyon, France, 2013.

[2] J. Sarnat, P. Koutrakis and H. Suh, "Assessing the Relationship between Personal Particulate and Gaseous Exposures of Senior Citizens Living in Baltimore, MD," Journal of the Air \& Waste Management Association, vol. 50, no. 7, pp. 1184-1198, 2000.

[3] D. Crouse, M. Goldberg and N. Ross, "A prediction-based approach to modelling temporal and spatial variability of traffic-related air pollution in Montreal, Canada," Atmos Environ, vol. 43, no. 32, p. 5075-5084, 2009.

\footnotetext{
${ }^{15}$ http://fishbain.net.technion.ac.il - will be available upon acceptance for publication
} 
[4] C. Pope, R. Burnett, M. Thun, E. Calle, D. Krewski, K. Ito and G. Thurston, "Lung Cancer, Cardiopulmonary Mortality, and Long-term Exposure to Fine Particulate Air Pollution," JAMA, vol. 287, no. 9, p. 1132-1141, 2002.

[5] B. Bishoi and A. Prakash, "A Comparative Study of Air Quality Index Based on Factor Analysis and USEPA Methods for an Urban Environment," Aerosol and Air Quality Research, vol. 9, no. 1, pp. 1-17, 2009.

[6] S. Rao, V. Chirkov, F. Dentener, R. Dingenen, S. Pachauri, P. Purohit, M. Amann, C. Heyes, P. Kinney, P. K. Z. Kolp, K. Riahi and W. Schoepp, "Environmental Modeling and Methods for Estimation of the Global Health Impacts of Air Pollution," Environmental Modeling \& Assessment, vol. 17, no. 6, pp. 613-622, 2012.

[7] European Environment Agency, "Assessment and Management of Urban Air Quality in Europe," Office for Official Publications of the European Communities, Denmark, 1998.

[8] P. Kanaroglou, M. Jerrett, J. Morrison, M. Bernardo Beckerman, A. Arain, N. Gilbert and J. Brook, "Establishing an air pollution monitoring network for intra-urban population exposure assessment: a location-allocation approach," Atmos. Environ., vol. 39, no. 13, p. 2399-2409, 2005.

[9] J. R. Stetter and J. Li, "Amperometric gas sensors a review," Chemical reviews, vol. 108, no. 2, pp. 352-366, 2008.

[10] A. Bard and L. Faulkner, Electrochemical Method: Fundamentals and Application, 2 ed., New-York, NY, USA: John Wiley \& Sons, 2001.

[11] M. Mead, O. Popoola, G. Stewart, P. Landshoff, M. Calleja, M. Hayes, J. Baldovi, M. McLeod, T. Hodgson, J. Dicks, A. Lewis, J. Cohen, R. Baron, J. Saffell and R. Jones, "The use of electrochemical sensors for monitoring urban air quality in low-cost, high-density networks," Atmospheric Environment, vol. 70, pp. 186-203, 2013.

[12] J. Ulanowski, P. Kaye, E. Hirst, A. Wieser and W. Stanley, "Miniature, low-cost optical particle counters.," in Int. Conf. Optical Characterization of Atmospheric Aerosols, Smolenice, Slovakia, 2013.

[13] R. S. Gao, H. Telg, R. J. McLaughlin, S. J. Ciciora, L. A. Watts, M. S. Richardson, J. P. Schwarz, A. E. Perring, T. D. Thornberry, A. W. Rollins, M. Z. Markovic, T. S. Bates, J. E. Johnson and D. W. Fahey, "A light-weight, high-sensitivity particle spectrometer for PM2. 5 aerosol measurements," Aerosol Science and Technology, vol. 50, no. 1, pp. 88-99, 2016. 
[14] M. Carminati, L. Pedalàa, E. Bianchi, F. Nasonb, G. Dubini and L. Cortelezzi, "Capacitive detection of micrometric airborne particulate matter for solid-state personal air quality monitors," Sensors and Actuators A: Physical, vol. 219, pp. 80-87, 2014.

[15] M. Carminati, G. Ferrari and M. Sampietro, "Emerging miniaturized technologies for airborne particulate matter pervasive monitoring," Measurement, 2015.

[16] E. Lebret, "Error in exposure measures," Toxicol Indust Health, vol. 6, p. 147-156, 1990.

[17] M. Jerret, A. Arain, P. Kanaroglou, B. Beckerman, D. Potoglou, T. Sahsuvaroglu, J. Morrison and C. Giovis, "A review and evaluation of intraurban air pollution exposure models," Journal of Exposure Analysis and Environmental Epidemiology, vol. 15, pp. 185-204, 2005.

[18] R. Ballantyne, J. Fien and J. Packer, "Program Effectiveness in Facilitating Intergenerational Influence in Environmental Education: Lessons From the Field," The Journal of Environmental Education, vol. 32, no. 4, pp. 8-15, 2010.

[19] Y. Ma, M. Richards, M. Ghanem, Y. Guo and J. Hassard, "Air Pollution Monitoring and Mining Based on Sensor Grid in London," Sensors, vol. 8, no. 6, pp. 3601-3623, 2008.

[20] The European Parliament and the Council of the European Union, "Directive 2008/50/EC on ambient air quality and cleaner air for Europe," Official Journal of the European Union, pp. L152/1-L152/44, 21 May 2008.

[21] S. Molchanov, I. Levy, Y. Etzion, U. Lerner, D. Broday and B. Fishbain, "On Distributed Air Quality Measurements with Micro Sensors," Science of the Total Environment, vol. 502, pp. 537-547, 2015.

[22] R. Bonney, H. Ballard, R. Jordan, E. McCallie, T. Phillips, J. Shirk and C. C. .. Wilderman, "Public Participation in Scientific Research: Defining the Field and Assessing Its Potential for Informal Science Education," 2009.

[23] J. Shirk, H. Ballard, C. Wilderman, T. Phillips, A. Wiggins, R. Jordan, E. McCallie, B. Lewenstein, M. Krasny and R. Bonney, "Public Participation in Scientific Research : a Framework for Deliberate Design," Ecology and Society, vol. 17, no. 2, 2012.

[24] R. Williams, V. Kilaru, E. Snyder, A. Kaufman, T. Dye, A. Rutter, A. Russell and H. Hafner, "Air Sensor Guidebook," National Exposure Research Laboratory, Office of Research and Development, U.S. Environmental Protection Agency, Research Triangle Park, NC, USA, 2014.

[25] CITI-SENSE Project, "Home Page," 2015. [Online]. Available: http://www.citi-sense.eu. [Accessed 01 04 2015]. 
[26] D. Lee and D. Lee, "Environmental gas sensors 1 (3), 214-224.," IEEE Sensors Journal, vol. 1, no. 3, pp. 214-224, 2001.

[27] T. Becker, S. Muhlberger, C. Braunmuhl, G. Muller, T. Ziemann and K. Hechtenberg, "Air pollution monitoring using tin-oxide-based micro-reactor system," Sensors Actuators B, vol. 69, p. 108-119, 2000.

[28] D. Williams, G. Henshaw, M. Bart, G. Laing, J. Wagner, S. Naisbitt and J. Salmond, "Validation of lowcost ozone measurement instruments suitable for use in an air-quality monitoring network," Measurment Science and Technology, vol. 24, no. 6, pp. 5803-5814, 2013.

[29] U. Lerner, T. Yacobi, I. Levy, S. Moltchanov, T. Cole-Hunter and B. Fishbain, "The effect of ego-motion on environmental monitoring," Science of the Total Environment, vol. 533, pp. 8-16, 2015.

[30] R. Piedrahita, Y. Xiang, N. Masson, J. Ortega, A. Collier, Y. Jiang, K. Li, R. Dick, Q. Lv, M. Hannigan and L. Shang, "The next generation of low-cost personal air quality sensors for quantitative exposure monitoring 7, 33," Atmos. Meas. Tech., vol. 7, pp. 3325-3336, 2014.

[31] N. Rabinovitch, M. Strand and E. Gelfand, "Particulate Levels Are Associated with Early Asthma Worsening in Children with Persistent Disease," American Journal of Respiratory and Critical Care Medicine, vol. 173, no. 10, pp. 1098-1105, 2006.

[32] G. Kyrkilis, A. Chaloulakou and P. Kassomenos, "Development of an aggregate Air Quality Index for an urban Mediterranean agglomeration: Relation to potential health effects," Environment International, vol. 33, no. 5, pp. 670-676, 2007.

[33] M. Kendall, Rank Correlation Methods, London: Charles Griffin \& Company Limited, 1948.

[34] W. Daniel, "Kendall's tau," in Applied Nonparametric Statistics, Boston, PWS-Kent, 1990, pp. 365377.

[35] J. Myers, A. Well and R. L. Jr, "Inference, assumptions, and power in multiple regression," in Research Design and Statistical Analysis, New-York, NY, USA, Lawrence Erlbaum, 2010, pp. 551-572.

[36] B. Fishbain and E. Moreno-Centeno, "Self Calibrated Wireless Distributed Environmental Sensory Networks," Scientific Reports, in press.

[37] D. Carslaw, S. Beevers, K. Ropkins and M. Bell, "Detecting and quantifying aircraft and other onairport contributions to ambient nitrogen oxides in the vicinity of a large international airport," Atmospheric Environment, vol. 40, no. 28, pp. 5424-5434, 2006. 
[38] E. Westmoreland, N. Carslaw, D. Carslaw, A. Gillah and E. Bates, "Analysis of air quality within a street canyon using statistical and dispersion modelling techniques," Atmospheric Environment, vol. 41, no. 39, pp. 9195-9205, 2007.

[39] A. Jones, R. Harrison and J. Baker, "The wind speed dependence of the concentrations of airborne particulate matter and Nox," Atmospheric Environment, vol. 44, no. 13, pp. 1682-1690, 2010.

[40] D. Carslaw and K. Ropkins, "Openair d An R package for air quality data analysis," Environmental Modelling \& Software, Vols. 27-28, pp. 52-61, 2012.

[41] L. Yaroslavsky, Theoretical Foundations of Digital Imaging Using MATLAB, CRC Press, 2012.

[42] P. Pokorná, J. Hovorka, M. Klán and P. K. Hopke, "Source apportionment of size resolved particulate matter at a European air pollution hot spot," Science of the Total Environment, vol. 502, no. 1, pp. 172-183, 2015.

[43] R. Zhang, J. Jing, J. Tao, S.-C. Hsu, G. Wang, J. Cao, C. Lee, L. Zhu, Z. Chen and Y. a. o. Zhao, "Chemical characterization and source apportionment of PM 2.5 in Beijing: seasonal perspective," Atmospheric Chemistry and Physics, vol. 13, no. 14, pp. 7053-7074, 2013.

[44] S. Arya, Air pollution meteorology and dispersion, New-York, NY, USA: Oxford University Press, 1999.

[45] P. Zannetti, Air pollution modeling: theories, computational methods and available software, Springer Science \& Business Media, 2013.

[46] G. Kyrkilis, A. Chaloulakou and P. Kassomenos, "Development of an aggregate Air Quality Index for an urban Mediterranean agglomeration: Relation to potential health effects," Environment International, vol. 33, no. 5, pp. 670-676, 2007.

[47] Y. Katznelson, "Ch. 1 - Fourier Series on T," in An Introduction to Harmonic Analysis, Cambridge, UK, Cambridge University Press, 2004, pp. 1-54.

[48] M. Boas, Mathematical Methods in the Physical Sciences, Hoboken, NJ, USA: John Wiley \& Sons, 2006.

[49] W. Tsujita, A. Yoshino, H. Ishida and T. Moriizumi, "Gas sensor network for air-pollution monitoring," Sensors Actuators B, vol. 110, pp. 304-311, 2005.

[50] AQMesh, UK, "AQMesh Website," July 2015. [Online]. Available: http://www.aqmesh.com/. [Accessed July 2015]. 
[51] H. Yoshikado and M. Tsuchida, "High levels of winter air pollution under the influence of the urban heat island along the shore of Tokyo Bay," Journal of Applied Meteorology, vol. 35, no. 10, pp. 18041813, 1996.

[52] J. H. Seinfeld and S. N. Pandis, Atmospheric chemistry and physics: from air pollution to climate change, John Wiley \& Sons, 2016.

[53] N. Smirnov, "Table for estimating the goodness of fit of empirical distributions," Annals of Mathematical Statistics, vol. 19, pp. 279-281, 1948.

[54] T. B. Arnold and J. W. Emerson, "Nonparametric Goodness-of-Fit Tests for Discrete Null Distributions," The R Journal, vol. 3, no. 2, pp. 34-39, 2001.

[55] N. Zumel and J. Mount, Practical Data Science with R, Shelter Island, NY, USA: Manning, 2014.

[56] A. Tarantola, Inverse problem theory and methods for model parameter estimation, SIAM, 2005. 